\title{
Primary Intramedullary Hydatid cyst
}

\section{Ashish Jung Thapa $M S^{1}$, Asheesh Tandon $M C h^{2}$, Alok Agrawal $M C h^{3}$}

${ }^{1,2,3}$ Centre for minimally Invasive Brain and Spine Surgery, Aditya Super-specialty Hospital, Jabalpur, Madhya Pradesh, India.

\section{Abstract}

Hydatid cysts or Hydatid disease is caused by Echinococcus granulosus infestation. Dogs, wolves, and other carnivores are the definitive host, and human being the accidental intermediate hosts. This disease commonly involves the liver and lungs and rarely involves other organs of the body. Primary intramedullary hydatid cysts are extremely rare and few cases before us have been reported in the literature. There is no pathognomonic sign or symptom for spinal hydatid cyst, mostly compression related symptoms, e.g. radiculopathy, myelopathy, local pain, and pathologic fractures are found. So preoperative diagnosis of spinal hydatid requires the correlation of all the aspects including clinical features, radiology, and lab reports. Surgical management is the best treatment for spinal hydatid cyst with complete excision without cyst rupture being the primary target along with complete neural elements decompression. Here we report a case of a 26-year old male with paraparesis with MRI finding directing towards $\mathrm{D}_{9}-\mathrm{D}_{10}$ intramedullary cystic lesion (cystic astrocytoma) which was completely excised and histopathology report favored intramedullary hydatid cyst.

Key words: Antihelmintic, Endemic, Hydatid cyst, Intramedullary

\section{Introduction}

$\mathrm{H}^{\mathrm{s}}$ ydatid cysts or Hydatid disease is caused by Echinococcus granulosus infestation. The dog, wolf, and other carnivorous animals are the definitive host and release the eggs in the feces. Intermediate hosts such as humans, sheep, and cattle ingest the eggs,

\section{Access this article online \\ Website: https://www.nepjol.info/index.php/NJN \\ DOI: https://doi.org/10.3126/njn.v18i1.34970 \\ HOW TO CITE}

Thapa AJ, Tandon A, Agrawal A. Primary Intramedullary Hydatid cyst. NJNS. 2021;18(1):70-72.

'ORCID id: 0000-0002-1571-604X

${ }^{2}$ ORCID id: 0000-0002-7215-1612

${ }^{3}$ ORCID id: 0000-0003-3733-4162

\author{
Address for correspondence: \\ Dr Ashish Jung Thapa, MS \\ Centre for minimally Invasive Brain and Spine Surgery, \\ Aditya Super-specialty Hospital, \\ Napier Town, Jabalpur 482002, Madhya Pradesh, India \\ E-mail: zenith_horizan@yahoo.com \\ Phone: +91-9691808598
}

Copyright (C) 2021 Nepalese Society of Neurosurgeons (NESON)

ISSN: 1813-1948 (Print), 1813-1956 (Online)

This work is licensed under a Creative Commons Attribution-Non Commercial 4.0 International License. humans in direct contact with the definitive host or through contaminated food with the parasite eggs get this disease. The larvae phase (metacestodes) of the tapeworm Echinococcus granulosus causes a hydatid cyst in humans. Mediterranean region, East Europe, East Africa, Central Asia, and South American countries, Australia and New Zealand are the endemic areas for this disease. ${ }^{1}$ This disease most commonly involves the liver (50-70\%), lungs $(20-30 \%)$, and brain (2-4\%) but occasionally the heart, bone, or other organs of the body are involved as well. ${ }^{2,3}$ Only $0.5-1 \%$ of spinal hydatid cyst has been found where $90 \%$ of them are confined to the vertebrae and the epidural space. ${ }^{3}$ Spinal hydatid cyst as classified by Braithwaite and Lees into five types are (1) primary intramedullary hydatid cyst, (2) intradural extramedullary hydatid cyst, (3) extradural intraspinal hydatid cyst, (4) hydatid disease of the vertebrae, and (5) paravertebral hydatid disease. ${ }^{4}$ Here we report a case of rare primary intramedullary hydatid cyst of the Dorsal spine, very few cases of intramedullary hydatid cyst have been reported before us. Surgical management is the best treatment for spinal hydatid cyst with almost no recurrence after complete unruptured excision of the lesion.

\section{Case Report}

A 26 years old male wheelchair bounded, comes to our outpatient with complaints of numbness in right lower limb progressing up to inguinal region for 3 months, left lower limb numbness 45 days, nocturnal low back pain, 
weakness in the right lower limb more than left, bowel and bladder retention urinary catheterization. On the clinical survey, he was found to have paraparesis most prominent in the right lower limb. His general condition was fair, he had right lower limb power 1/5 and left was $3 / 5$. His reflexes were brisk with loss of sensation from $\mathrm{D}_{10}$ downwards $20-40 \%$, bowel/bladder- retention, gaitwheelchair-bound, tone- spastic in lower limbs. His history and other investigations were insignificant. MRI showed $\mathrm{D}_{9}-\mathrm{D}_{10}$ well defined intramedullary thick wall enhancing mass lesion with cord edema likely cystic astrocytoma, Figure 1(A).

After initial assessment and medical clearance, the patient was taken for surgery, using a posterior approach. $\mathrm{D}_{9}-\mathrm{D}_{10}$ laminectomy was performed and a whitish cystic lesion with severe cord compression was seen. The cyst was excised as a whole, following continuous irrigation. Intraoperative local dexamethasone irrigation was done. The dura was closed watertight. The wound was closed in layers. The histopathological examination confirmed the hydatid cyst as the diagnosis.

No anthelmintic was initiated preoperative as MRI differentials didn't indicate towards hydatid cyst, however, albendazole $400 \mathrm{mg}$ twice a day for 1 month was started immediate postoperative. The patient's paraplegia improved drastically postoperatively. He could walk with support on 2 weeks follow up and without any support and his power at 12 months follow up was $5 / 5$ on all limbs with sensation intact and normal bowel and bladder, and radiological evaluation showed no evidence of disease recurrence Figure 1(B).

\section{Discussion}

Hydatid cysts can involve any part of the body. Primary intramedullary hydatid cysts are extremely rare and few cases before us have been reported in the literature. Churrier in 1807 described the first case of the hydatid cyst of the spine. ${ }^{5,6}$ There is no pathognomonic sign or symptom for spinal hydatid cyst, mostly compression related symptoms, e.g. radiculopathy, myelopathy, local pain, and pathologic fractures are found. So preoperative diagnosis of spinal hydatid requires the correlation of all the aspects including clinical features, radiology, and lab reports. Nowadays, specific ELISA/Western blot is about $80 \%$ to $100 \%$ specific and $88 \%$ to $96 \%$ sensitive in hepatic

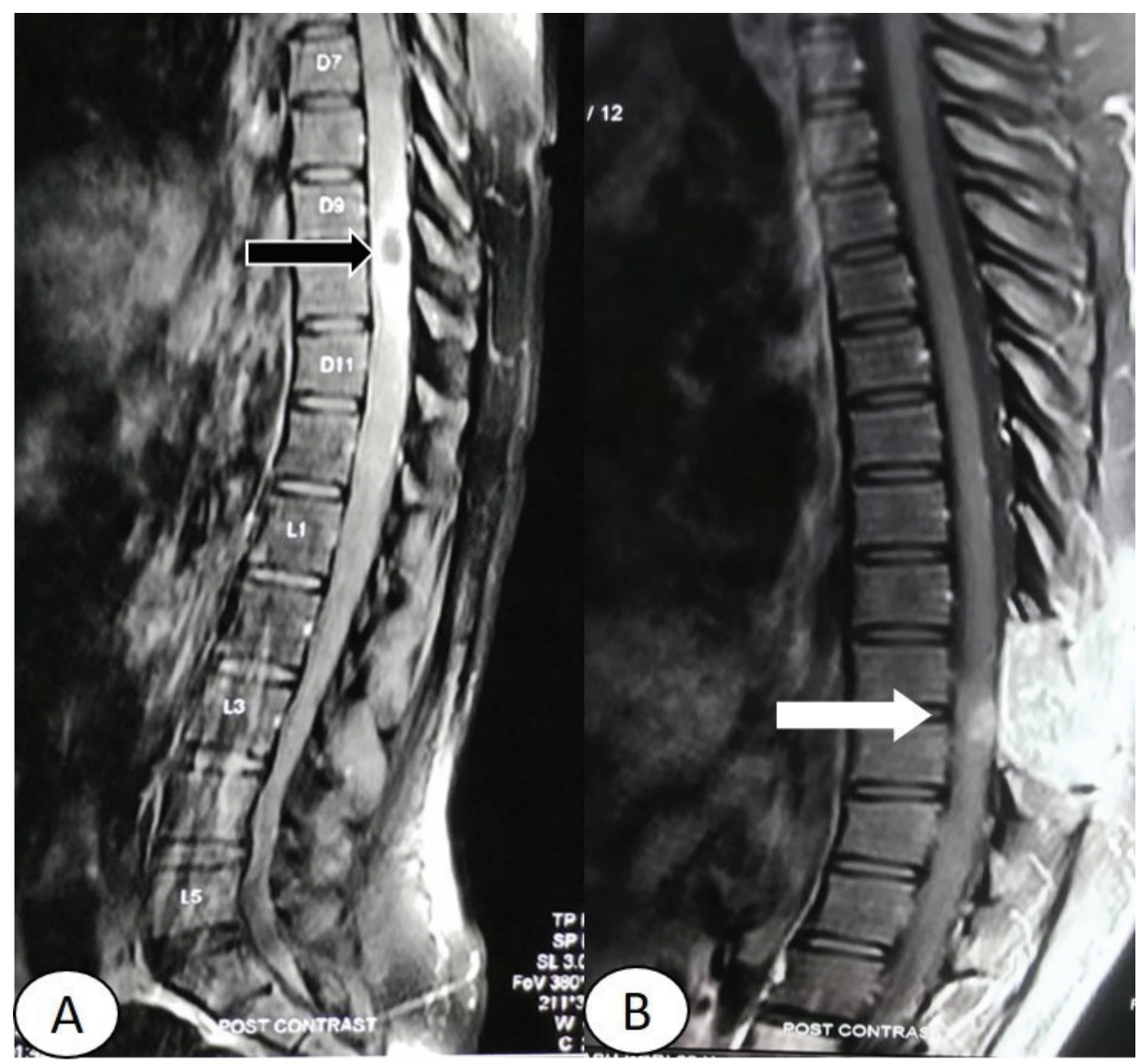

Figure 1. (A) Post-contrast T1W shows intramedullary SOL at $D_{9}-D_{10}$ (Black arrow). (B) Post-contrast T1W scan at 2 weeks follow-up with post-operative changes and no left-over mass (white arrow). 
hydatid cyst infections yet it is less sensitive in other organs (25\% to $56 \%$ ), which makes the diagnosis even more challenging. 6 ,7 Differential diagnosis of intramedullary cystic lesions include cystic astrocytoma, ependymoma, hematoma, arachnoid cyst, and epidermoid cyst. This challenge of differential diagnosis was faced in our case report being in the non-endemic region the diagnosis directed more towards the other cystic intramedullary lesion and antihelmintic was initiated postoperatively.

Surgical techniques today have been at their best and with the advancement of microsurgery, total excision of the intramedullary lesion can be achieved. The recurrence of the hydatid cyst is high if the cyst wall ruptures and the contents spill, so not only total removal but without cyst rupture should be the primary target of the operating surgeon. ${ }^{8}$ The cystic content may also trigger a variety of hypersensitivity reactions, such as pruritus, urticaria, edema, dyspnea, asthma, vomiting, diarrhea, colicky abdominal pain, and even anaphylactic shock. ${ }^{8}$ Surgical excision for neural decompression must also be prioritized as most clinical signs and symptoms are due to compression of the spinal cord and or the associated roots. Recommended anthelmintic therapy for hydatid disease is albendazole $400 \mathrm{mg}$ twice daily for 28 days, which can preoperatively decrease cyst pressure as well as preventing recurrence of the cyst. Postoperative anthelmintic therapy for at least one year is also recommended to avoid further relapses. ${ }^{6,9}$ Spinal Hydatid cyst can lead to paraparesis, quadriparesis, severe disabilities, and even death in some cases. So, prevention and control are the best way to reduce its burden in regional endemic areas. Deworming of dogs, promoting public education, meat inspection, and early diagnosis and proper follow-up of the affected patients are important ways to prevent and control hydatid disease. ${ }^{6,10}$ The recurrence rate is reported at $30-40 \%$. The cyst becomes fertile in 6-9 months, which is a key time window for estimating recurrence. ${ }^{8}$

\section{Conclusion}

Primary intramedullary hydatid cyst being extremely rare can mimic other spinal cystic lesions both clinically and radiologically. Surgery with complete removal of the cyst without rupture is the mainline treatment of the primary intramedullary hydatid cyst. The recurrence rate is low with complete unruptured removal of the cyst and long term postoperative antihelmintic agents.

Conflict of Interest: None

Source(s) of support: None

\section{References}

1. Bayar MA, Erdem Y, Habip N. Primary intraspinal extradural hydatid disease causing radicular compression. Turk Neurosurg 1997; 7:33-5.

2. Delibaş SB, Ozkoç S, Sahin S, Aksoy U, Akisü C. Dokuz Eylül Universitesi Tip Fakültesi Parazitoloji Anabilim Dali Seroloji Laboratuvari'na Kistik Ekinokokkozis şüphesiyle başvuran hastalarin değerlendirilmesi [Evaluation of patients presenting with a suspicion of cystic echinococcosis to the serology laboratory of the Parasitology Department of Dokuz Eylül University Medical Faculty]. Turkiye Parazitol Derg. 2006;30(4):279-81. Turkish. PMID: 17309027.

3. Senol MG, Tekeli H, Kendirli MT, Kaya S, Turhan $\mathrm{V}$, Sonmez G, et al. Intramedullary hydatid cyst of the cervical spine. Indian $\mathrm{J}$ Med Microbiol. 2012;30(4):480-1. https://doi.org/10.4103/02550857.103780

4. Braithwaite PA, Lees RF. Vertebral hydatid disease: radiological assessment. Radiology. 1981;140(3):7636. https://doi.org/10.1148/radiology.140.3.7280247

5. Gopal N, Chauhan S, Yogesh N. Primary spinal extradural hydatid cyst causing spinal cord compression. Indian J Orthop. 2007;41(1):76-8. https://doi.org/10.4103/0019-5413.30531

6. Moradi-Tabriz H, Motevalli D, Pourrashidi Boshrabadi A, Mahdavi A, Eftekhar-Javadi A. Intradural Intramedullary Spinal Hydatid Cyst Mimicking Cystic Malignancy: A Case Report, Arch Clin Infect Dis. 2018; 13(3): e62365. https://doi. org/10.5812/archcid.62365

7. Karadereler S, Orakdogen M, Kilic K, Ozdogan C. Primary spinal extradural hydatid cyst in a child: case report and review of the literature. Eur Spine J. 2002;11(5):500-3. https://doi.org/10.1007/s00586002-0411-0

8. Zhang Z, Fan J, Dang Y, Xu R, Shen C. Primary intramedullary hydatid cyst: a case report and literature review. European Spine Journal. https:// doi.org/10.1007/s00586-016-4896-3

9. Ley AJ, Marti A. Intramedullary hydatid cyst. Case report. J Neurosurg. 1970;33(4):457-9. https://doi. org/10.3171/jns.1970.33.4.0457

10. Karakasli A, Yilmaz M, Mucuoglu AO, Yurt A. A large primary dumbbell hydatid cyst causing neural foraminal widening of the thoracic spine: A case report and literature review. Int J Surg Case Rep. 2015;8C:55-8. https://doi.org/10.1016/j. ijscr.2014.12.036 